\title{
CONVERSES OF A DISCRETE WIRTINGER TYPE INEQUALITY
}

\section{LENG TUO AND FENG YONG}

Abstract. In this paper, we establish the following converse of Alzer's inequality, which is a discrete analogue of Wirtinger's inequality: Let $z_{1}, z_{2}, \cdots, z_{n}(n \geqslant 2)$ be complex numbers with

$$
\sum_{k=1}^{n} z_{k}=0
$$

then

$$
\sum_{k=1}^{n}\left|z_{k}\right|^{2} \geqslant \lambda(n) \min _{1 \leqslant k \leqslant n}\left\{\left|z_{k+1}-z_{k}\right|^{2}\right\}
$$

where $z_{n+1}=z_{1}$ and $\lambda(n)=\frac{n}{4}$, for even $n ; \lambda(n)=\frac{n}{4 \sin ^{2} \frac{(n-1) \pi}{2 n}}$, for odd $n$. The constant $\lambda(n)$ is best possible.

Mathematics subject classification (2010): 26D15, 65D10.

Keywords and phrases: Wirtinger's inequality, Alzer's inequality, discrete analogue of integral inequality.

\section{REFERENCES}

[1] R. P. Agarwal, V. ČUlJaK And J. PeČArić, On discrete and continuous Wirtinger inequalities, Appl. Anal. 70 (1998), 195-204.

[2] H. Alzer, A continuous and a discrete variant of Wirtinger's inequality, Math. Pannon. 3 (1992), $83-89$.

[3] V. Bangert, M. G. Katz, S. Shnider And S. Weinberger, E7, Wirtinger inequalities, Cayley 4-form, and homotopy, Duke Math. J. 146 (2009), 35-70.

[4] H.D. BLock, Discrete analogues of certain integral inequalities, Proc. Amer. Math. Soc. 8 (1957), $852-859$.

[5] J.B. DiaZ And F.T. MetCaLF, Variations of Wirtinger's inequality, in: Inequalities (O. Shisha, ed.), 79-103, New York, 1967.

[6] Z. Ditzian, Generalizations of the Wirtinger-Northcott inequality, Bull. London Math. Soc. 35 (2003), 455-460.

[7] K. FAn, O. TAUSSKY AND J. TOdD, Discrete analogs of inequalities of Wirtinger, Monatsh. Math. 59 (1955), 73-90.

[8] A. M. FInK, Discrete inequalites of generalized Wirtinger type, Aequationes Math. 11 (1974), 31-39.

[9] G. Hardy, J. E. Littlewood and G. Pólya, Inequalities, Cambridge Univ. Press, Cambridge/New York, 1951.

[10] G. V. Milovanović and I. Z. Milovanović, On discrete inequalities of Wirtinger's type, J. Math. Anal. Appl. 88 (1982), 378-387.

[11] J. NovotnA, Variations of discrete analogues of Wirtinger's inequality, Časopis Mat. 105 (1980), 278-285.

[12] B. G. PachPatte, A note on Opial and Wirtinger type discrete inequalities, J. Math. Anal. Appl. 127 (1987), 470-474.

[13] I. J. Schoenberg, The finite Fourier series and elementary geometry, Amer. Math. Monthly 57 (1950), 390-404.

[14] C. A. SwAnson, Wirtinger's inequality, SIAM J. Math. Anal. 9 (1978), 484-491. 
[15] X. M. Zhang, A refinement of the discrete Wirtinger inequality, J. Math. Anal. Appl. 200 (1996), 687-697. 